\title{
Application of Ultrasonography to Non-invasive Sexing Based on the Sexual Dimorphism in Gonads of Immature Barfin Flounder Verasper moseri
}

\author{
Takahiro Matsubara, ${ }^{* 1}$ Ken-ichi Watanabe, ${ }^{* 2}$ Takeshi Yamanome, ${ }^{* 3}$ \\ and Takaaki Kayaba*4 \\ ${ }^{*}$ Hokkaido National Fisheries Research Institute, Katsurakoi, Kushiro, Hokkaido 085-0802, Japan \\ ${ }^{* 2}$ Akkeshi Station of Japan Sea Farming Association, Chikushikoi, Akkeshi, Hokkaido 088-1108, Japan \\ ${ }^{*}$ Iwate Fisheries Technology Center, Heita, Kamaishi, Iwate 026-0001, Japan \\ ${ }^{* 4}$ Hokkaido Institute of Mariculture, Shikabe, Hokkaido 041-1404, Japan
}

(Received August 10, 1998)

\begin{abstract}
An ultrasonographic technique for non-invasive sexing of barfin flounder Verasper moseri was established based on sexual dimorphism of gonadal appearence. We used here a high frequency transducer $(10 \mathrm{MHz})$ attaching to ultrasonography to improve echoic images. Although gonads of 23month-old males were impossible to discern, those of females were visible as bright oval contours in the ultrasonographic images. Accurate identification of sex was accomplished in 63 fish ranged from 204 to $274 \mathrm{~mm}$ in total length of 14-month-old fish, 288 to $401 \mathrm{~mm}$ of 19-month-old fish and 252 to $370 \mathrm{~mm}$ of 23-month-old fish, except for three false diagnosis. On the other hand, it was difficult to determine sex in 11-month-old fish, $98-135 \mathrm{~mm}$ in total length, by this technique. The present results indicate the practical usefulness of ultrasonography for a rapid, non-invasive and realtime sexing of immature flounders.
\end{abstract}

Key words: ultrasound, ultrasonography, sexing, flounder, teleost

Barfin flounder Verasper moseri is a large flat fish inhabiting cold sea basins around east Hokkaido. This species is promising for aquaculture and resources enhancement in northern Japan due to its high commercial value. Available methods for non-invasive sexing are desired for keeping the large adult barfin flounders rationally in limited numbers of aquaria of fry-producing facilities. Identification of sex in an early stage and management of the sex ratio in the rearing fish are also important to economize the costs for culturing the candidates of spawning adults. The sex ratio of juvenile barfin flounder easily incline toward male-rich by rearing environment, especially affected by high water temperature, during the period of sex differentiation. ${ }^{* 5}$

At present, only a few available methods for sexing have been developed. Among them, immunological detections of maturing female-specific proteins, e.g. vitellogenin ${ }^{1-6)}$ and choriogenin ${ }^{7-9)}$ in sera or surface mucous, are thought to be potent practical methods for identifying maturing females. However, they are limited in application to only sub-adult or adult fish and it takes more than a few hours to get the results by these methods. On the other hand, an ultrasonographic method has been introduced as a realtime and non-invasive sexing for sub-adult Atlantic salmon Salmo salar ${ }^{10)}$ and mature adult coho salmon Oncorhynchus kisutch ${ }^{11)}$ on the basis of morphological differences of gonads between sexes.

Flat fish including barfin flounder show definite sexual dimorphism in external shape of gonads from immature stage. This characteristic enhances the usefulness of ultrasonography for sexing of flounder by imaging nondeleteriously the gonadal shape. In the present study, we established a method to identify sex in immature barfin flounder using a high-resolution ultrasonography. The size dependence limit for correct diagnosis is also regarded by examining different sizes of fish.

\section{Materials and Methods}

\section{Fish}

Immature barfin flounders used in the present study were kept at the following three facilities. (1) 16 individuals of 19-month-old and 20 individuals of 23-month-old barfin flounders, $252-370 \mathrm{~mm}$ and $252-370 \mathrm{~mm}$ in total length, respectively, were from Akkeshi Station of Japan Sea Farming Association. (2) 30 individuals of 14-monthold barfin flounders, $204-274 \mathrm{~mm}$ in total length, were from Iwate Fisheries Technology Center. (3) 32 individuals of 11-month-old barfin flounders, $98-135 \mathrm{~mm}$ in total length, were from Hokkaido Institute of Mariculture.

\section{Instrument}

An ultrasonic Echo Camera SSD-1000 (Aloka Inc. ${ }^{* 6}$ ) with a $10 \mathrm{MHz}$ annular array transducer, ASU-36WL-10, was used to scan immature barfin flounders. Transducers at a relatively high frequency promise high resolution but 
restricted depth of penetration and are used for clinical diagnosis of superficial or sub-surface tissues. The annular array transducer generate a cross-section image of the interfaced object $38 \mathrm{~mm}$ in width at the surface and $57 \mathrm{~mm}$ at the depth of $25 \mathrm{~mm}$ on a display.

\section{Experiments}

The ultrasonographic observation was performed by means of the following two experiments. In both experiments, fish were placed on the bottom of a shallow plastic tray covered by a foam rubber plate to eliminate reflection of scattered ultrasound. They were scanned by attaching the transducer head directly on the skin of fish without any ultrasonic coupling gel. Scans were made transversely at various positions of the abdominal sides moving laterally.

Experiment 1 was carried out to ascertain the non-invasiveness of the ultrasonographic scanning using live 19month-old barfin flounders without anesthesia at Akkeshi Station of Japan Sea Farming Association. After judging gender from the ultrasonographic images, fish were inplanted with radio identification tags, HS5105L (Denstron/IDI, Inc) and kept in a $50 \mathrm{k} l$ aquarium for one week. Then, the fish were killed and total body length was measured, and then dissected to confirm the judgement. The ovary length was also measured in the case of females.

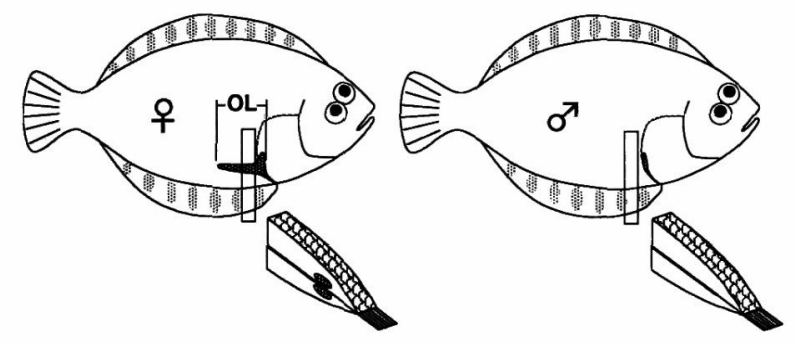

Fig. 1. A schematic drawing demonstrating morphological and positional differences of gonads between sexes in 23-month-old barfin flounders.

Gonads are indicated as dark shades. Rectangles reveal the scanning positions of ultrasonographic observations. OL: ovary length.
Experiment 2 was carried out to examine the size dependence limit for correct diagnosis using three groups (11-, 14-, and 23-month-old) of different sized barfin flounders. In this experiment, we used dead fish for the experiment because of the convenience of transportation from different facilities. After ultrasonographic diagnosis, fish were treated the same as in experiment 1.

\section{Results}

\section{Ultrasonographic Observation of Gonads of Barfin Flounder}

Figure 1 shows schematic drawings demonstrating morphological differences of gonads between sexes and the scanning positions of ultrasonographic observations of both sexes of 23-month-old immature barfin flounders. Ovary of the fish extends into the secondary coelom located between hemal spines of caudal vertebrae and abdominal muscle as in the other flat fish. On the other hand, immature testis along the first pterygiophore of anal fin, which lines the rear end of the coelomic cavity, never extends into the secondary coelom.

Next, the typical ultrasonographic images of the transverse sections of abdominal trunks of both sexes at the position just after the first pterygiophore of anal fin are presented in Fig. 2. In females, a pair of clear oval contours with slight internal hyperechoic area were observed attached to a bright image of the hemal spine of caudal vertebrae (Fig. 2A). The oval contours appeared beneath the hypoechoic area of the abdominal muscle and were easily distinguishable from bright contours of interheminal spine and motive muscles of anal fin. On the contrary, no oval contours were observed in males (Fig. 2B). The position, length, diameter and depth from the surface of the oval contours in females coincided well with the anatomical data of the ovaries measured after dissection. The oval contour was thus suggested to be the echoic image of the surface of ovary.

\section{Experiment 1}

On the basis of the above criterion, trials of ultrasono-
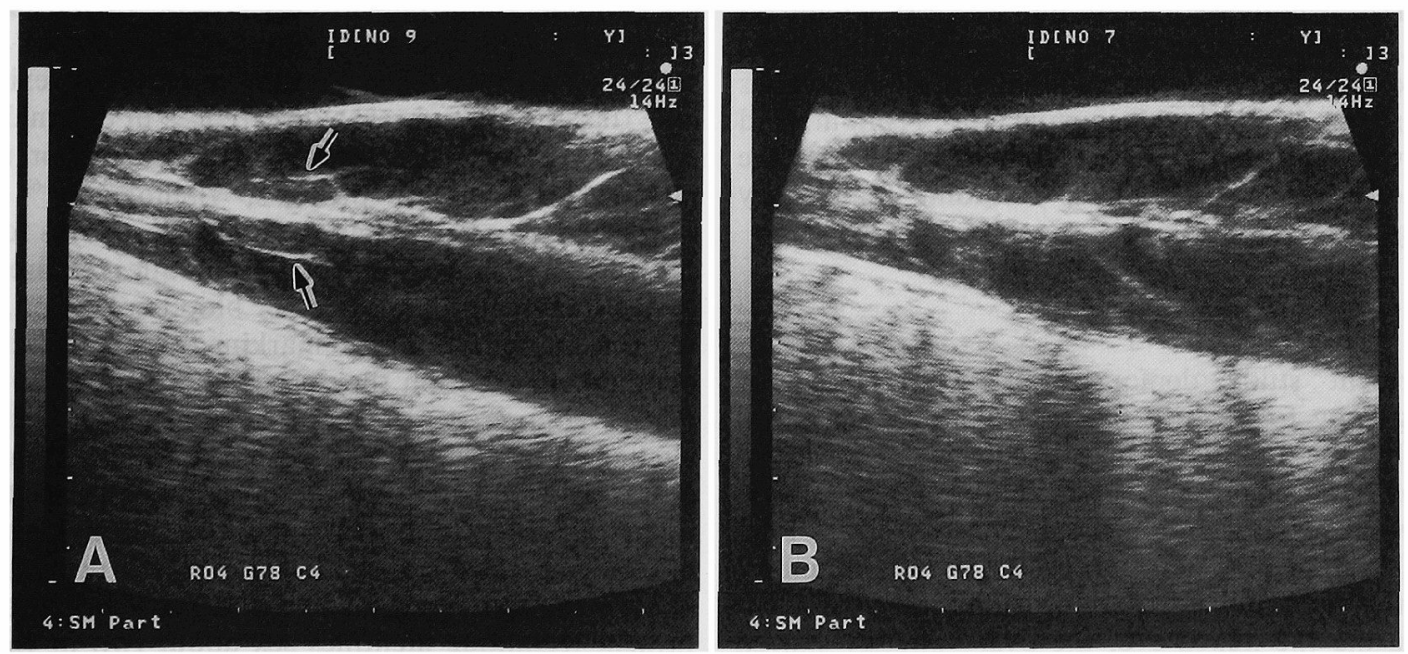

Fig. 2. Ultrasonographic images of abdominal transverse section from 23-month-old female (A) and male (B) barfin flounders. A pair of bright oval contours of ovaries (arrows) are seen in the image from the female. 
Table 1. Result of ultrasonographic sexing in live 19-month-old barfin flounders

\begin{tabular}{|c|c|c|c|c|c|c|c|}
\hline Sex & No. used & $\begin{array}{l}\text { Total length }(\mathrm{mm}) \\
\text { mean } \pm S D\end{array}$ & $\begin{array}{l}\text { Body weight }(\mathrm{g}) \\
\text { mean } \pm \mathrm{SD}\end{array}$ & $\begin{array}{l}\text { Gonad weight }(\mathrm{g}) \\
\text { mean } \pm \mathrm{SD}\end{array}$ & $\begin{array}{l}\text { Ovary length }(\mathrm{mm}) \\
\text { mean } \pm S D\end{array}$ & $\begin{array}{l}\text { One week after } \\
\text { Condition }\end{array}$ & Diagnistic accuracy \\
\hline Female & 6 & $354 \pm 32$ & $711 \pm 235$ & $2.88 \pm 1.13$ & $40 \pm 3$ & live & $100 \%$ \\
\hline Male & 10 & $346 \pm 32$ & $638 \pm 195$ & $0.14 \pm 0.07$ & & live & $80 \%$ \\
\hline
\end{tabular}

Table 2. Result of ultrasonographic sexing in immature barfin flounders

\begin{tabular}{|c|c|c|c|c|c|c|}
\hline \multirow{2}{*}{ Group } & \multirow{2}{*}{ No. used } & \multicolumn{2}{|c|}{ Total length (mm) } & \multicolumn{2}{|c|}{ Ovary length (mm) } & \multirow{2}{*}{ Diagnistic accuracy } \\
\hline & & mean $\pm S D$ & range & mean $\pm S D$ & range & \\
\hline 23-month-old & 20 & $297 \pm 30$ & $252-370$ & & & $100 \%$ \\
\hline Female & 11 & $295 \pm 17$ & $262-319$ & $33 \pm 4$ & $28-42$ & \\
\hline Male & 9 & $300+41$ & $252-370$ & & & \\
\hline 14-month-old & 30 & $235 \pm 17$ & $204-274$ & & & $97 \%$ \\
\hline Female & 20 & $242 \pm 15$ & $218-274$ & $23 \pm 4$ & $15-30$ & \\
\hline Male & 10 & $222 \pm 14$ & $204-242$ & & & \\
\hline 11-month-old & 32 & $115 \pm 10$ & $98-135$ & & & - \\
\hline Female & 6 & $115 \pm 14$ & $98-134$ & $7 \pm 1$ & $5-8$ & \\
\hline Male & 26 & $115 \pm 9$ & $102-135$ & & & \\
\hline
\end{tabular}

graphic sexing were carried out using live 19-month-old fish. Instead of anesthesia, the eyes of the fish were covered with a wet towel paper to keep them still. It took within two minutes to judge the gender by the ultrasonographic images. After one week, there seemed to be no injury in all the fish and ascertained the non-deleteiousness of the ultrasonographic scanning. The result of the experiment is listed in Table 1 . The gender of $88 \%$ individuals was correctly detected following the above mentioned criterion, however, two males were falsely diagnised. The failure may likely be caused by an acumulated fat layer, which also yields a bright contour, at the same position to the ovary.

\section{Experiment 2}

The size dependence limit for correct diagnosis was evaluated using the three different size groups (Table 2). In 23month-old and 14-month-old fish, the gender of $100 \%$ and $97 \%$ of individuals, respectively, was correctly detected. Their ovarian lengths were $28-42 \mathrm{~mm}$ and $15-30 \mathrm{~mm}$, respectively. The false diagnosis of a 14-month-old female seemed likely to be due to an undergrowth of its ovaries (ovary length: $16 \mathrm{~mm}$ ). Meanwhile, in 11-month-old juveniles with $5-8 \mathrm{~mm}$ ovaries, we could not detect the oval contours in any individuals including females by ultrasonography.

\section{Discussion}

The present study demonstrates the potential of ultrasonography to identify the sex of immature barfin flounder by the use of a high frequency transducer. Gonads of flat fish reveal distinct morphological differences between sexes, size, appearance and position, even in juvenile stage. In 11-month-old barfin flounder, although the testis did not develop sufficiently for identification using the naked eye, the ovary already started elongation toward the caudal fin and grew to $4.8-6.0 \%$ of the total body length (Table 2). The basis of existence (female) or absence (male) of the gonads behind the coelomic cavity would be a particular advantage for correct gender determination ultrasonographically. Moreover, the flat body and sub-surface localization of ovary in flounders permit us to use a high-frequency transducer which is pointed out to give a better resolution. ${ }^{10,11)}$ Ovaries were visualized as bright oval contours in 23-, 19-, and 14month-old fish with ovary length more than $15 \mathrm{~mm}$. The failure of recognition of an echoic image of ovary in 11month-old juveniles indicates that the sizes of the ovaries are less than the limit of ultrasonographic sexing. Combining the result of the other two groups, the size dependent limit of this technique was suggested to exist around $20 \mathrm{~cm}$ in total length and $15 \mathrm{~mm}$ in ovary length.

Sexual dimorphism in genomic, morphological, physiological and endocrinological levels allow possibilities for identifying genomic or phenotypic sex. For example, identification of sex chromosomes ${ }^{12)}$ and sex specific genes ${ }^{13,14)}$ are applicable to detect the genomic sex in some fish having genomic dimorphism. Observation of morphological differences between sexes, e.g. adipose fin of Atlantic salmon, ${ }^{15)}$ also would be a potent method for sexing in the case that the species reveal differences in external appearance. At present, immunological detection or measurement of sex specific proteins, vitellogenin ${ }^{1-6)}$ and sex steroids $^{16)}$ are proposed as available procedures for practical sexing of fish. However, the techniques require some invasive treatments, puncture for blood collection, or wipe for mucous collection, and marking for identification of individual. In addition they need time from three hours to one day and restrict the maturity of fish after beginning of vitellogenesis. The present ultrasonographic technique requires only light anesthesia if any and allows real time sorting. Actually, it took less than a few minutes per individual to complete diagnosis. Barfin flounder primarily spawn at three or four years of age in captivity. Therefore, the present technique identifies sex about two or three years retroactive to their first spawning and one to two years earlier than the sexing techniques of vitellogenin and sex 
steroid measurements.

Early identification of sex in young fish would permit fry-production facilities to keep candidates of broodstock under appropriate sex ratio and allows more rational management with substantial saving of costs. The present ultrasonographic technique using high frequency transducer gives rise to the earliest sexing in flounders at present. Combination of this technique with high-growth rate culture after the period of sex differentiation would provide earlier sex determination in flounders under one year of age.

Acknowledgments The authors thank $\mathrm{H}$. Yukawa and other stuff of Aloka Inc., Asahikawa branch, Hokkaido, for their helpful suggestions, technical assistance and loan of ultrasound equipment. This study was supported financially by the Fisheries Agency, Ministry of Agriculture, Forestry and Fisheries, Japan.

\section{References}

1) P. Y. Le Bail and B. Breton: Rapid determination of the sex of puberal salmonid fish by a technique of immunoagglutination. Aquaculture, 22, 367-375 (1981).

2) M. R. Gordon, T. G. Owen, T. A. Ternan, and L. D. Hildebrand: Measurement of a sex-specific protein in skin mucus of premature coho salmon (Oncorhynchus kisutch). Aquaculture, 43, 333-339 (1984).

3) H. Ohta, Y. Shinriki, M. Honma, A. Hara, T. Matsubara, T. Azumaya, and K. Yamauchi: Early distinction of the sex of hatchery-reared masu salmon, Oncorhynchus masou, using antiserum against egg yolk protein. Sci. Rep. Hokkaido Fish Hatchery, 39, 67-74 (1984) (in Japanese).

4) T. Matsubara and K. Sawano: Sex determination of Pacific halibut (Hippoglossus stenolepis Schmidt) by the immunodot-blotting technique using antiserum against vitellogenin. Bull. Hokkaido Natl. Fish. Res. Inst., 56, 17-26 (1992) (in Japanese).

5) A. Takemura: Vitellogenin-like substance in the skin mucus of tilapia Oreochromis mossambicus. Fisheries Sci, 60, 789-790 (1994).

6) A. Takemura, M. Kanematsu, and M. Oka: Early sex determina- tion in greater amberjack Seriola dumerili using skin mucus. Nippon Suisan Gakkaishi, 62, 62-67 (1996).

7) S. J. Hyllner, B. Norberg, and C. Haux: Isolation, partial characterization, induction, and the occurrence in plasma of the major vitelline envelope proteins in the Atlantic halibut (Hippoglossus hippoglossus) during sexual maturation. Can. J. Fish. Aquat. Sci., 51 1700-1707 (1994).

8) D. O. Oppen-Berntsen, S. O. Olsen, C. J. Rong, G. L. Taranger, P. Swanson, and B. T. Walther: Plasma levels of eggshell zr-proteins, estradiol-17 $\beta$, and gonadotropins during an annual reproductive cycle of Atlantic salmon (Salmo salar). J. Exp. Zool., 268, 59-70 (1994).

9) M. Shimizu, T. Fujita, N. Hiramatsu, and A. Hara: Immunochemical detection, estrogen induction and occurrence in serum of vitelline envelope-related proteins of Sakhalin taimen Hucho perryi. Fisheries Sci., 64, 600-605 (1998).

10) N.S. Mattson: A new method to determine sex and gonad size in live fishes by using ultrasonography. J. Fish Biol., 39, 673-677 (1991).

11) R. W. Martin, J. Myers, S. A. Sower, D. J. Phillips, and C. McAuley: Ultrasonic imaging, a potential tool for sex determination of live fish. North Am. J. Fish. Manage., 3, 258-264 (1983).

12) H. G. Thorgaard and J. E. Disney: Chromosome preparation and analysis, in "Methods for Fish Biology" (ed. by C. B. Schreck and P. B. Moyle), American Fisheries Society, Maryland, USA, 1990, pp. 171-190.

13) R. H. Devlin, B. K. McNeil, T. D. D. Groves, and E. M. Donaldson: Isolation of a Y-chromosomal DNA probe capable of determining genetic sex in chinook salmon (Oncorhynchus tshawytscha). Can. J. Fish. Aquat. Sci., 48, 1606-1612 (1991).

14) I. Nakayama, F. Foresti, R. Tewari, M. Schartl, and D. Chourrout: Sex chromosome polymorphism and heterogenic males revealed by two cloned DNA probes in the $\mathrm{ZW} / \mathrm{ZZ}$ fish Leporinus elongatus. Chromosoma, 103, 31-39 (1994).

15) T. F. Næsje, L. P. Hansen, and T. Järvi: Sexual dimorphism in the adipose fin of Atlantic salmon, Salmo salar L. J. Fish Biol., 33, 955-956 (1988).

16) G. B. Sangalang, H. C. Freeman, and R. B. Flemming: A simple technique for determining the sex of fish by radioimmunoassay using 11-ketotestosterone antiserum. Gen. Comp. Endocrinol., 36, 187-192 (1978). 